\title{
Empresas Exponenciais: um Estudo de Caso sobre o Clima Organizacional
}

\author{
Exponential Companies: A Case Study on the Organizational Climate
}

\section{Empresas Exponenciales: Un Estudio de Caso sobre el Clima Organizacional}

Taiz Regina Balardin Antonini ${ }^{1}$ taiz@unochapeco.edu.br http://lattes.cnpq.br/3192240695093197 https://orcid.org/0000-0002-9898-2799

Andrea Bencke Zambarda ${ }^{1}$ zambarda@unochapeco.edu.br http://lattes.cnpq.br/7828042895517314 https://orcid.org/0000-0001-5882-1117 


\title{
Resumo
}

O objetivo deste estudo foi analisar as características do clima organizacional em uma empresa exponencial. A empresa escolhida para estudo foi a Renovigi Energia Solar, localizada no munício de Chapecó (SC). Trata-se de um estudo de caso, com pesquisa descritiva, com enfoque qualitativo, que teve como instrumento de coleta de dados entrevistas com roteiro semiestruturado para uma amostra intencional envolvendo alguns gestores e colaboradores. O estudo traz dados quanto a avaliação individual e percepção dos colaboradores acerca de diversos quesitos relacionados ao clima, estrutura organizacional, benefícios, vantagens e satisfação pessoal. Verificou-se que as percepções dos colaboradores são extremamente positivas, otimistas e estão alinhadas aos objetivos da empresa. Além disso, as condições de trabalho oferecidas pela empresa, suas características de gestão, bem como, os benefícios, a autonomia, as perspectivas e linhas de crescimento seguem modelos de empresa com características exponencias. Diferente das empresas tradicionais, os ambientes de trabalho e os meios de tecnologias utilizados para gestão e tomada de decisões são extremamente ágeis e modernos. Isso reflete nas condições de trabalho, nos planos salariais e metas desenvolvidas com cada colaborador. Identificou-se um clima positivo, com alto valor sentimental para os colaboradores, e que faz brilhar os olhos quando se fala em carreira e permanência na empresa. A tecnologia tem papel fundamental para o desenvolvimento diário das ações, inobstante a isso, identifica-se uma preocupação muito grande com as pessoas, suas competências e desenvolvimento, principalmente com sua satisfação e vontade em querer estar e permanecer fazendo parte dos times - assim definido pelos gestores.

Palavras-chave: Organização exponencial. Clima organizacional. Equipes. Liderança.

\section{Exponential Companies: A Case Study on the Organizational Climate}

\begin{abstract}
The aim of this study was to analyze the characteristics of the organizational climate in an exponential company. The company chosen for the study was Renovigi Energia Solar, located in the municipality of Chapecó (SC). It is a case study, with descriptive research, with a qualitative focus, which had as a data collection instrument interviews with a semi-structured script for an intentional sample involving some managers and collaborators. The study provides data on the individual assessment and perception of employees about various issues related to climate, organizational structure, benefits, advantages and personal satisfaction. It was found that the perceptions of employees are extremely positive, optimistic and are aligned with the company's objectives. In addition, the working conditions offered by the company, its management characteristics, as well as the benefits, autonomy, perspectives and lines of growth follow company models with exponential characteristics. Unlike traditional companies, the work environments and technologies used for management and decision making are extremely agile and modern. This is reflected in working conditions, salary plans and goals developed with each employee. A positive atmosphere was identified, with high sentimental value for employees, and that makes the eyes shine when it comes to career and permanence in the company. Technology plays a fundamental role in the daily development of actions, regardless of this, a great concern with people, their skills and development is identified, especially with their satisfaction and willingness to want to be and remain part of the teams - as defined by managers.
\end{abstract}

Keywords: Exponential organization. Organizational climate. Teams. Leadership. 


\section{Empresas Exponenciales: Un Estudio de Caso sobre el Clima Organizacional}

\section{Resumén}

El objetivo de este estudio fue analizar las características del clima organizacional en una empresa exponencial. La empresa elegida para el estudio fue Renovigi Energia Solar, ubicada en el municipio de Chapecó (SC). Se trata de un estudio de caso, con investigación descriptiva, con enfoque cualitativo, que tuvo como instrumento de recolección de datos entrevistas con un guión semiestructurado para una muestra intencional que involucró a algunos gerentes y colaboradores. El estudio aporta datos sobre la valoración y percepción individual de los empleados sobre diversos temas relacionados con el clima, la estructura organizativa, los beneficios, las ventajas y la satisfacción personal. Se encontró que las percepciones de los empleados son sumamente positivas, optimistas y están alineadas con los objetivos de la empresa. Además, las condiciones laborales que ofrece la empresa, sus características de gestión, así como los beneficios, autonomía, perspectivas y líneas de crecimiento siguen modelos de empresa con características exponenciales. A diferencia de las empresas tradicionales, los entornos de trabajo y las tecnologías que se utilizan para la gestión y la toma de decisiones son extremadamente ágiles y modernos. Esto se refleja en las condiciones laborales, planes salariales y metas desarrolladas con cada colaborador. Se identificó un ambiente positivo, con alto valor sentimental para los empleados, y que hace brillar los ojos a la hora de carrera y permanencia en la empresa. La tecnología juega un papel fundamental en el desarrollo diario de las acciones, independientemente de esto, se identifica una gran preocupación por las personas, sus habilidades y desarrollo, especialmente con su satisfacción y voluntad de querer ser y seguir siendo parte de los equipos - como se define por los gerentes.

Palabras clave: Organización exponencial. Clima organizacional. Equipos. Liderazgo. 


\section{INTRODUÇÃO}

Uma organização exponencial é aquela cujo impacto no mercado e crescimento é desproporcionalmente elevado em relação às tradicionais, em geral, dez vezes maior que as demais empresas. Além disso, a principal diferença entre as instituições tradicionais e as exponenciais está na sua hierarquia, enquanto uma valoriza a centralização do poder e tem baixa aceitação ao risco, a outra valoriza a descentralização e autonomia, bem como a experimentação de novas experiências (Ismail, Malone, \& Geest, 2019).

Seguindo as ideias do autor, verifica-se que se está em uma nova geração de organizações, que estão se expandindo e gerando valor num ritmo nunca visto antes. É dado início a era das startups de bilhões de dólares e, em breve, das corporações de trilhões de dólares, onde as melhores empresas e organizações se moverão praticamente na velocidade da luz.

São as pessoas, aliadas à tecnologia, que estão dinamizando esta nova realidade organizacional, por meio das suas competências, vinculadas a sua motivação e engajamento trazem as inovações desse novo cenário.

Neste contexto, é importante reconhecer e identificar os processos de gestão de pessoas, bem como as condições e características do clima organizacional deste modelo de organização, visto que possuem formas modernas e altamente tecnológicas em todos os seus processos.

Ismail et al. (2019) afirmam que a gestão destas empresas segue um modelo totalmente disruptivo em relação aos modelos conservadores e tradicionais, que prioriza o uso da tecnologia, inovação e criatividade. Inovação e criatividade são competências dos seres humanos e tratam-se de variáveis dependentes relacionadas ao nível de motivação das pessoas para que ocorra a entrega dessas competências à organização.

O tema em questão suscita a importância de conhecer e estudar sobre o clima organizacional dessas empresas exponenciais. Clima organizacional é tido como um termômetro de satisfação e motivação das pessoas no trabalho e o quanto esse pode trazer de resultados eficazes para a organização.

Maximiano (2009) reforça o conceito, enfatizando que o clima organizacional, em essência, é uma medida de como as pessoas se sentem em relação à empresa e seus administradores, tendo seu conceito evoluído para o conceito de qualidade de vida no trabalho.

Diante deste cenário, tem-se como problema central deste estudo: quais são as principais características do clima organizacional em uma empresa exponencial?

Este artigo tem como objetivo analisar as principais características do clima organizacional de empresas com crescimento exponencial tendo como cenário de estudo a experiência da empresa Renovigi Energia Solar, localizada no munícipio de Chapecó, no Oeste do estado de Santa Catarina.

A Renovigi é uma empresa brasileira que investe forte em uma inovação transformadora. Nasceu em 2012, como resultado da reunião de empresários com histórias de décadas de sucesso à frente de suas organizações, que possuem em comum uma visão focada em desenvolver e oferecer ao mercado soluções que agregam a inovação e a sustentabilidade. 
Atuam em todo o território nacional com soluções para sistemas conectados à rede, com a maior rentabilidade possível para diversos portes de clientes.

Justifica-se a relevância e importância deste estudo na perspectiva em que se busca conhecer características relacionadas à gestão de pessoas em uma empresa de crescimento exponencial, identificando diferenciais inovadores nos seus processos de gestão, tomada de decisões, formação e qualificação de seu capital intelectual e, especialmente, nas características do clima organizacional. Os conhecimentos frutos deste estudo podem ser referência para outros modelos de negócios já existentes e/ou a serem implementados.

\section{REVISÃO TEÓRICA}

Neste tópico estão apresentadas as ideias centrais sobre a importância das pessoas como capital intelectual das organizações, clima organizacional, papel dos líderes e o processo de mudanças, assim como uma revisão sobre organizações exponenciais que nortearão, na sequência, as análises deste estudo.

\subsection{A importância das pessoas como capital intelectual das organizações}

O reconhecimento em relação ao quanto as pessoas são importantes nas organizações é algo praticamente inquestionável pelos gestores e estudiosos sobre o tema. Conforme destacam Matos e Lopes (2008), o capital intelectual está tornando-se o fator de produção mais importante, deixando para trás os fatores tradicionais da fórmula da produtividade, que era o capital e a mão de obra.

Druker (1993 como citado por Matos \& Lopes (2008) corrobora com este assunto esclarecendo que, no passado, as fontes de vantagem competitiva eram o trabalho e os recursos naturais, agora e no próximo século, a chave para construir a riqueza das nações é o conhecimento.

Hsieh (2010, p. 167) cita que, "para manter a cultura forte, queríamos nos certificar de contratar apenas pessoas com quem também gostássemos de sair, fora do escritório", dando a entender que a relação interpessoal dos colaboradores é extremamente importante para o fortalecimento da organização, valorizando as pessoas e, consequentemente, o capital intelectual.

A valorização deste conceito, que destaca o capital intelectual, evolui a cada ano, e vem escrevendo a história global, tendo como mastro a economia mundial, que se destaca cada vez mais em função de uma sociedade que valoriza o conhecimento e os recursos gerados por ela.

No entanto, Matos e Lopes (2008) afirmam que as organizações sempre procuraram e valorizaram o conhecimento, mas "a novidade está no reconhecimento de que o conhecimento é um ativo que é necessário gerir com a mesma atenção dedicada aos demais ativos". Continuam afirmando que é preciso cultivar um clima de inovação e criatividade, que permita a formação de conhecimento, o qual deve poder ser incutido na cultura organizacional, nos valores e nas crenças, levando à disseminação do conhecimento e à inovação.

Muitas organizações, principalmente aquelas ligadas à produção do conhecimento, destacamse por possuírem ativos intangíveis, sendo esses mais valiosos do que os bens tangíveis, mensurados em valores determinados. Para Sveiby (1998), os ativos intangíveis contribuem 
muito mais para o valor do produto final do que os ativos tangíveis. Já Stewart (1998) afirma que a quantidade de termos intangíveis está relacionada ao conhecimento do corpo funcional da organização e a capacidade de ele inovar diante de um ambiente competitivo, compondo o cenário atual das organizações. Percebe-se que este assunto é debatido há muitos anos, mas só agora ganha força no modelo de gestão das organizações.

Para Hsieh (2010, p. 170), "passamos os anos seguintes focando na melhoria da experiência do cliente, reforçando nossa cultura e investindo no desenvolvimento pessoal e profissional dos nossos funcionários". Isso demonstra que essa cultura de valorização e construção de um corpo de colaboradores efetivos leva tempo e demanda investimento, exigindo dos gestores clareza nos objetivos e metas organizacionais, criando um clima organizacional propício para o sucesso deste modelo de gestão organizacional, pois, como afirma Hsieh (2010, p. 174), "é um gasto de curto prazo para um investimento de longo prazo".

\subsection{Clima organizacional, o papel do líder e as mudanças}

Uma organização existe pela vontade de pessoas, assim também acontece com seus processos de crescimento e sustentabilidade. Grande parte do que ocorre dentro das organizações está relacionada ao clima organizacional e a cultura nela instalada. Pessoas empreendedoras, líderes, com boa comunicação, pensamento crítico, criativo e inovador, que aceitam correr riscos, possivelmente, são responsáveis pelo crescimento exponencial das organizações.

Para Robbins, Judge e Sobral (2010), o clima organizacional faz menção das percepções que os colaboradores de uma organização têm sobre ela e seu ambiente de trabalho.

Segundo Luz (2003, p. 12): "O clima organizacional é o reflexo do estado de ânimo ou do grau de satisfação dos funcionários de uma empresa, num dado momento".

Pode-se classificar como dois tipos o clima organizacional dentro das organizações, ou seja, pode ser bom ou prejudicado/ruim. "O clima é bom quando predominam as atitudes positivas que dão ao ambiente de trabalho uma tônica favorável e é prejudicado ou ruim quando algumas variáveis organizacionais afetam de forma negativa e duradoura o ânimo da maioria dos funcionários" (Luz, 2003, p. 46).

De acordo com Bergamini (2008 como citado em Fernandes \& Rosa, 2013), quando uma pessoa começa a trabalhar em uma empresa, ela está com um alto nível de motivação, pois está cheia de expectativas e planos com o novo trabalho. Neste contexto, torna-se fundamental, novamente, o papel do gestor com a preocupação em criar estratégias para mantê-lo motivado, pois a falta de satisfação causa problemas relacionados à integridade do colaborador, impactando diretamente no desenvolvimento das atividades, atitudes comportamentais e automaticamente no bom clima da organização.

Fernandes e Rosa (2013, p. 02) afirmam que são as motivações do ambiente organizacional que irão definir o clima organizacional "que é favorável quando proporciona a satisfação das necessidades pessoais dos colaboradores e desfavorável quando causa frustração dessas necessidades". Continuando neste mesmo aspecto, o autor enfatiza que quando o funcionário está motivado no trabalho, este sentimento se sobressai em relação à remuneração e ao crescimento na carreira. Os colaboradores buscam empresas nas quais se sintam pertencentes e tenham ciência que sua função é importante para a organização. 
Chiavenato (2010) afirma que o clima organizacional é uma atmosfera do ambiente de trabalho que é constituído por pessoas. Este ambiente é relacionado à moral e satisfação das necessidades destes indivíduos podendo ser: saudável ou doentio, quente ou frio, negativo ou positivo, satisfatório ou insatisfatório. $\mathrm{O}$ autor contribui ainda afirmando que o clima organizacional é favorável quando proporciona satisfação das necessidades pessoais, produzindo elevação do moral interno, e considera desfavorável quando proporciona frustração daquelas necessidades.

O clima organizacional está diretamente relacionado com a percepção que grupo de colaboradores possuem em relação ao ambiente de atuação da organização, refletindo a imagem da organização, desde aspectos financeiros, políticos, formas de gestão, liderança, bem como, as diferentes percepções de cada colaborador.

Neste contexto, é inegável que o papel do líder é extremamente importante, conduzindo situações e processos de forma que todos possam ter a oportunidade de dedicar-se ao máximo na busca de novos e bons resultados organizacionais. Para Maximiano (2009, p. 289), "liderança é o uso da influência não coercitiva para dirigir as atividades dos membros de um grupo e levá-los à realização de seus próprios objetivos". Afirma ainda que "a pessoa que comanda com sucesso seus colaboradores para alcançar finalidades específicas é um líder". Complementa dizendo que "um grande líder é aquele que tem essa capacidade dia após dia, ano após ano, numa grande variedade de situações" (Maximiano, 2009, p. 289). Baseando-se nesta definição do que é um líder, entre tantas definições existentes, conclui-se que líder é alguém que consegue desenvolver, gerenciar e acompanhar equipes, a fim de alcançar objetivos comuns.

Para Silva (2008, p. 235), “o clima organizacional é uma função de muitas variáveis, que incluem ações do gerente, comportamento dos empregados, fatores internos e externos da organização". Afirma ainda que "os comportamentos observados nas organizações são reflexo dos estilos de liderança".

Conforme Rachel e Salomão (2011, p. 5), um clima favorável dentro da empresa será um fator positivo a fim de compatibilizá-la com o bom desempenho, o que produzirá uma empresa ágil, criativa, competidora e geradora de bons resultados e satisfação a todos os envolvidos. Além disso, explicam que se chegar a um clima favorável torna-se necessário uma gestão de pessoas e relações adequadas, gerando um impacto positivo no desempenho, buscando aumentar a produtividade com expectativas de fornecer à empresa funcionários estáveis, satisfeitos, motivados e produtivos.

\footnotetext{
É importante também estimular e proporcionar oportunidade de desenvolvimento profissional para os funcionários. A empresa não passa da fase de apenas cobrar qualificação do quadro funcional, mas passa a incentivar. Pode-se fazer isso por meio de treinamentos internos e externos, auxílio financeiro nos estudos (faculdade, curso de línguas, cursos profissionalizantes específicos etc.); intercâmbios profissionais, programas de desenvolvimento, e outros. A valorização dos funcionários é um catalisador de bons resultados. (Rachel \& Salomão, 2011, p. 11).
}

Neste contexto, seguindo o raciocínio de Rachel e Salomão (2011), um bom clima organizacional pode promover uma evolução das relações de trabalho, conectando as pessoas na missão de melhorar a ambiência organizacional, alterando e transformando os mais diferentes aspectos que efetivamente podem alavancar o sucesso organizacional. 
Em um cenário no qual, a cada dia, dezenas de empresas são compradas, vendidas ou se fundem e onde a concorrência não se limita mais ao quarteirão imediato, a networking é um importante capital social, por isso deve começar a montar a sua.

Para Oliveira (2010), apenas o discurso de "vamos mudar" não é mais suficiente, pois a mudança não é produto, e sim o processo de buscar destacar-se entre os concorrentes diretos, criando diferenciais e alcançando posições menos vulneráveis, dando mais segurança ao negócio e às pessoas que vivem nele. É importante que os processos de mudança não sigam de encontro a ninguém, principalmente dos que tomam decisões, por isso, estarem todos comprometidos é fundamental para obter-se êxito. $\mathrm{O}$ autor afirma ainda que "qualquer processo de mudança, fica severamente comprometido se colidir com os objetivos pessoais de alguém com muito poder na organização". Iniciar um processo de mudança e revertê-lo é criar uma dificuldade adicional para retomá-lo mais adiante.

Dentro deste contexto, Oliveira (2010) reforça que um processo de mudança deve obrigatoriamente estar relacionado a uma necessidade identificada e reconhecida por todos. Se for necessário reverter os resultados do negócio, o processo torna-se mais fácil porque as mudanças tendem a ser inevitáveis e prementes de crise, e, é claro, o sentimento de urgência.

Ainda, em outras circunstâncias, as necessidades de mudança não são tão visíveis e, nessas situações, o que faz a diferença é sua percepção da oportunidade e sua capacidade de compartilhar essa percepção com a liderança.

É preciso muita determinação, energia e coragem para implantar as mudanças. Também, absoluto e sincero comprometimento do líder com o processo, com a clara visão de aonde queremos ir e o que queremos ser.

\subsection{Organizações Exponenciais}

O conceito Organização Exponencial (ExO) surgiu em 2008, na Singularity University (SU), em uma conferência da NASA no Vale do Silício. Logo, em 2014, aparece a partir do referencial teórico dos autores Salim Ismail, Michael S. Malone e Yuri Van Geest, com a publicação do livro "Organizações Exponenciais. Por que elas são 10 vezes melhores, mais rápidas e mais baratas que a sua (e o que fazer a respeito)".

O tema traz para a reflexão o estudo das organizações que crescem numa proporção muito maior, quando comparadas a empresas tradicionais, crescendo até dez vezes mais rápido que seus concorrentes. Essas empresas estão baseadas, principalmente, na inovação, apresentando benefícios extraordinários para o negócio, acumulando ganhos de forma crescente e acelerada.

\footnotetext{
Uma Organização Exponencial (ExO) é aquela cujo impacto (ou resultado) é desproporcionalmente grande - pelo menos 10 vezes maior - comparado ao de seus pares, devido ao uso de novas técnicas organizacionais que alavancam as tecnologias aceleradas. Ao invés de usar exércitos de colaboradores ou grandes configurações físicas, as Organizações Exponenciais são construídas com base nas tecnologias da informação, que desmaterializam o que antes era de natureza física e o transfere para o mundo digital sob demanda. (Ismail et al., 2019, p. 19).
}

O autor continua mencionando que, ao invés de contratar e utilizar mão de obra de número expressivo de colaboradores ou investir em grandes estruturas físicas, as Organizações Exponenciais são constituídas especialmente com base nas tecnologias da informação. 
Estas organizações possuem estruturas organizacionais resilientes e flexíveis ao risco. Segundo Ismail et al. (2019, p. 51), as organizações exponenciais pensam grande e precisam sonhar alto, além disso, todas possuem um Propósito Transformador Massivo (PTM), pois "alguns pretendem transformar o planeta, outros apenas um setor produtivo. Mas a transformação radical é o objetivo fundamental". Ainda, as ExOs de hoje "declaram com sinceridade e confiança que pretendem realizar milagres".

As principais características das Organizações Exponenciais, conforme Ismail et al. (2019), é primeiramente possuir um PTM, bem como outros dez atributos, que refletem os mecanismos internos e externos que estão totalmente interligados para que se possa alcançar um crescimento exponencial. Ainda, para Ismail et al. (2019), estas organizações priorizam a tecnologia e a inovação em todos os processos do negócio e possuem seis características fundamentais para o crescimento, são elas: Digitalização, Dissimulação, Disrupção, Desmaterialização, Desmonetarização e Democratização, como elementos vitais na criação de seus produtos/serviços. O autor esclarece que utiliza o acrônimo SCALE para refletir os cinco fatores externos e IDEAS para os cinco fatores internos. "Nem todas as Organizações Exponenciais possuem todos os 10 atributos, mas quanto mais elas tiverem, mais expansíveis elas tendem a ser" (Ismail et al., 2019, p. 50).

Para o autor as características externas (SCALE) que definem uma Organização Exponencial são Staff on de-mand (pessoal sob demanda), Comunidade e Multidão, Algoritmo, Ativos alavancados e Engajamento. Já os fatores internos (IDEAS) são Interface, Dashboards (painel de controle), Experimentação, Autonomia, Tecnologias Sociais.

Ainda apresentando elementos acerca das características das Organizações Exponenciais, o PTM é o ponto mais forte destas instituições. Ismail et al. $(2019$, p. 52) explicam que o propósito permite um crescimento exponencial coerente, une as aspirações coletivas, atraem os melhores talentos de todo o ecossistema, suporta uma cultura cooperativa e não política, e permite a agilidade e a aprendizagem.

Segundo a teoria dos autores, parafraseada por Santos $(2018$, p. 83), o PTM representa o propósito da empresa, que, no caso de uma ExO, deve ser necessariamente grande e ambicioso. Todas elas possuem um objetivo fundamental de transformação radical, que é sempre inspirador e aspiracional, ao contrário das tradicionais.

\footnotetext{
Muito mais do que uma frase de efeito, o PTM é capaz de gerar um 'poder da atração', que inspira pessoas, comunidades, colaboradores e cria uma mobilização de impacto cultural e social. Isso significa que uma marca aspiracional ajuda a fidelizar clientes, a reduzir custos, acelera o crescimento e gera identificação com problemas mundiais e, principalmente, atinge pessoas dispostas a ajudar nesse movimento. (Geest, 2015 como citado por Santos, 2018, p. 83).
}

Para destacar de forma mais clara, Santos (2018, p. 82-83) disponibiliza um quadro comparativo, com as principais diferenças entre as instituições lineares e as exponenciais:

Quadro 1: Características das Organizações Lineares x Exponenciais

\begin{tabular}{|c|c|}
\hline \multicolumn{2}{|c|}{ Características } \\
\hline Organização Linear & \multicolumn{1}{c|}{ Organização Exponencial } \\
\hline Centrada em resultados financeiros & $\begin{array}{c}\text { Centrada em informação; gerida por propósito e } \\
\text { apurado sistema de controles de indicadores; }\end{array}$ \\
\hline
\end{tabular}

UFAMBR, Manaus, v. 3, n. 1, art. 1, pp. 01-20, janeiro-junho, 2021 http://www.periodicos.ufam.edu.br/ufambr 
Empresas Exponenciais: um Estudo de Caso sobre o Clima Organizacional

\begin{tabular}{|c|c|}
\hline $\begin{array}{c}\text { Estrutura de poder top-down e hierárquica, } \\
\text { setores e departamentos; }\end{array}$ & $\begin{array}{c}\text { Estrutura descentralizada, autonomia, grupos } \\
\text { pequenos e multidisciplinares; }\end{array}$ \\
\hline Pensamento sequencial e linear; & Pensamento destrutivo e exponencial; \\
\hline $\begin{array}{c}\text { Planejamento estratégico como } \\
\text { extrapolação do passado; }\end{array}$ & $\begin{array}{c}\text { Ciclos curtos de planejamento, utilização de } \\
\text { metodologias ágeis (ágile, canvas, startup } \\
\text { enxuta); }\end{array}$ \\
\hline Intolerância ao risco; & Tolerância e incentivo ao risco; \\
\hline $\begin{array}{c}\text { Inflexibilidade dos processos; burocracia; } \\
\text { Autonomia, experimentação, prototipagem; }\end{array}$ & Autonomia, experimentação, prototipagem; \\
\hline $\begin{array}{c}\text { Utilização de colaboradores em tempo } \\
\text { integral; }\end{array}$ & $\begin{array}{c}\text { Uso de profissionais e recursos sob demanda; } \\
\text { uso da comunidade; }\end{array}$ \\
\hline Possui e controla seus próprios ativos. & Utiliza ativos alavancados. \\
\hline
\end{tabular}
Fonte: Geest (2015 como citado por Santos, 2018, p. 82-83).

Uma empresa exponencial requer inovação e, para Drucker (1962), a inovação se baseia principalmente na criação de valor, seja na concepção de um novo produto ou serviço, seja na criação de uma nova necessidade ou na adequação de novas finalidades para velhos produtos. Entendendo a inovação como uma função básica para as empresas, o autor a considera um instrumento pelo qual os empreendedores exploram as mudanças e criam oportunidades para negócios ou serviços diferentes (Drucker, 1962).

Complementando essa visão, Tidd e Bessant (2015) afirmam que a inovação acontece através da habilidade de detectar as oportunidades e estabelecer relações para que estas lhe sejam proveitosas. Além disso, a inovação não consiste apenas na abertura de novos mercados, mas de novas formas de servir mercados já estabelecidos e maduros.

De acordo com Lemos (2008), o processo de inovação aumentou muito nas últimas décadas, sua velocidade alterou radicalmente o uso do tempo na economia, ou seja, ocasionou "uma crescente redução do tempo de produção de bens - por meio da utilização das novas tecnologias, formas organizacionais e técnicas de gestão da produção - e também de consumo dos bens - com a planejada diminuição do tempo de vida dos produtos" (Lemos 2008, p. 162). Dessa forma, observa-se a crescente articulação dentro das empresas e entre estas e outras organizações, em especial, as instituições de pesquisa.

A autora enfatiza sua visão caracterizando a inovação a partir de dois modelos, a inovação radical e a inovação incremental. Pode-se qualificar a inovação radical como o desenvolvimento e introdução de um novo produto, processo ou forma de organização da produção inteiramente nova. Esse tipo de inovação pode representar redução de custos e aumento de qualidade em produtos. Já as inovações incrementais referem-se à introdução de qualquer tipo de melhoria em um produto, processo ou organização da produção dentro de uma empresa, sem alteração na estrutura industrial. Muitas delas imperceptíveis para o consumidor e podem gerar crescimento, aumento da produtividade e qualidade, redução de custos e ainda possibilitam a ampliação das aplicações de um produto ou processo.

Tidd e Bessant (2015) ressaltam que existem diferentes graus de novidade no processo de inovação, que vão desde melhorias incrementais até mudanças realmente radicais que transformam a forma de como vemos ou usamos as coisas.

Tigre (2006 como citado por Mascarenhas Bisneto \& Lins 2015) amplia este conceito apresentando quatro tipos de mudanças tecnológicas: a mudança incremental, na qual ocorrem 
melhorias contínuas e modificações cotidianas; a mudança radical, em que ocorrem saltos descontínuos na tecnologia de produtos e processos; o novo sistema tecnológico, onde ocorrem mudanças que afetam mais de um setor e dão origem a novas atividades econômicas; e o novo paradigma tecnoeconômico, onde ocorrem mudanças que afetam toda a economia, envolvendo mudanças técnicas e organizacionais, alterando produtos e processos, criando novas indústrias e estabelecendo trajetórias de inovações por várias décadas.

Reforçando este contexto, Tidd e Bessant (2015) enfatizam que a inovação não ocorre por acaso e nem de forma isolada, há a necessidade de integrá-la ao contexto da organização, vinculando-a a procedimentos que vão desde estímulos à criatividade, aprendizado e conhecimento, à formação de parcerias e desenvolvimento organizacional alinhado à estratégia da organização.

\section{PROCEDIMENTOS METODOLÓGICOS}

Quanto aos objetivos, esta pesquisa caracteriza-se como um estudo de caso descritivo. Pesquisas de caráter descritivo estudam, em geral, características de determinados grupos. Estudos descritivos são utilizados quando se deseja descrever as características de um fenômeno (Richardson, 2014).

Gil (2010) complementa o conceito enfatizando que as pesquisas descritivas apresentam as características de determinadas populações ou variáveis, e possuem como objetivos centrais levantar opiniões atitudes e crenças, e utiliza-se de técnicas para estudar as características de um grupo, como idade, sexo, nível de escolaridade etc.

Para Beuren (2008), a pesquisa descritiva seria a intermediária entre a pesquisa exploratória e a pesquisa explicativa, identificando que essa não seria tão preliminar como a primeira, nem tão aprofundada quanto a segunda. Designa que descrever consiste em identificar, relatar, comparar, entre outros aspectos.

Em relação à abordagem do problema, a pesquisa caracteriza-se como qualitativa, no sentido de conhecer melhor o problema em questão, buscando que os envolvidos respondessem questões com relação aos dados coletados.

De acordo com Beuren (2008, p. 92), na "pesquisa qualitativa concebem-se análises mais profundas em relação ao fenômeno que está sendo estudado". Lakatos e Marconi (2011, p. 269) acrescentam que a metodologia qualitativa "preocupa-se em analisar e interpretar aspectos mais profundos, descrevendo a complexidade do comportamento humano. Fornece análise mais detalhada sobre as investigações, hábitos, atitudes e tendências do comportamento".

Este estudo tem como objetivo analisar as principais características do clima organizacional de uma empresa com crescimento exponencial, tendo como cenário de estudo a experiência da empresa Renovigi, localizada no município de Chapecó, no Oeste do estado de Santa Catarina.

A empresa é considerada exponencial devido estrutura organizacional, não somente em termos financeiros, mas pela estrutura moderna, tecnológica e com uma gestão de pessoas totalmente inovadora. De acordo com entrevista do CEO da empresa, concedida à revista 
Ambiente Energia (2019), "a empresa Renovigi é uma empresa com um crescimento atípico. Nos últimos 03 anos crescemos mais de $2.800 \%$ ".

A amostra da pesquisa caracteriza como intencional, e será constituída pelo gestor da área de Recursos Humanos e por quatro colaboradores, com tempo de casa entre um e cinco anos efetivados na empresa, objetivando conhecer e identificar tais características.

Beuren (2008) afirma que a amostragem intencional consiste em selecionar amostras com base em informações disponíveis e que representem a população.

Dmitruk (2012, p. 189) complementa que "o pesquisador precisa conhecer bem o assunto para poder dividi-lo, fazer testagens, pré-testes e, por meio destes analisar o atendimento dos objetivos do estudo".

Neste contexto, foram utilizados roteiros de entrevistas com questões semiestruturadas. Para Richardson (2014), este modelo de entrevista, ao invés de responder à pergunta por meio de diversas alternativas pré-formuladas, visa obter do entrevistado o que ele considera os aspectos mais relevantes de determinado problema e, por meio de uma conversação guiada, pretende-se obter informações detalhada. As entrevistas ocorreram durante o mês de maio de 2020, através do envio por e-mail do roteiro da entrevista e conversa através do aplicativo Google Meet. Devido ao momento de pandemia pelo Covid-19, não foi possível contato pessoal com o público-alvo da pesquisa.

A análise de dados se deu por meio da análise de conteúdo, que, conforme Minayo (2001), é compreendida muito mais como um conjunto de técnicas e constitui-se na análise de informações sobre o comportamento humano, possibilitando uma aplicação tanto em pesquisas qualitativas quanto em quantitativas.

\section{ANÁLISE DOS RESULTADOS}

Este estudo contou com a participação de cinco colaboradores da empresa, cujas informações e perfil dos entrevistados são mostrados a seguir.

Quadro 2: Perfil dos entrevistados

\begin{tabular}{|c|c|c|c|}
\hline Qualificação & Cargo & Idade & Tempo De Empresa \\
\hline Entrevistado 1 & Administrativo & 18 & 1 ano e quatro meses \\
\hline Entrevistado 2 & Administrativo & 22 & 1 ano e nove meses \\
\hline Entrevistado 3 & Administrativo & 26 & 2 anos \\
\hline Entrevistado 4 & Gestão & 25 & 5 anos \\
\hline Entrevistado 5 & Gestão & 36 & 5 anos \\
\hline
\end{tabular}

Fonte: dados da pesquisa (2020).

Ao analisar os dados obtidos por meio das entrevistas realizadas, percebe-se um perfil de colaboradores jovens, inclusive, ocupando cargos de gestão e direção na empresa. Este perfil jovem, inovador e empreendedor é apresentado por Ismail et al. (2019) como uma força potencial às organizações, pois muitas vezes os grandes executivos e membros de conselhos das empresas tradicionais estudaram nas mesmas escolas, possuem mesmas formações profissionais, alguns são de uma geração mais antiga e não entendem de tecnologias. Então, o autor afirma e recomenda aos CEOs de grandes empresas que aproximem os jovens dos 
cargos de liderança e façam que acompanhem posições de liderança para ajudar a fechar lacunas geracionais e tecnológicas.

O perfil inovador da organização vai dos benefícios, compostos pelo apoio à pós-graduação, aulas de inglês gratuito, plano de saúde, liberdade para execução das tarefas e horários, ao jeito de lidar com as pessoas, com calor humano, respeito, envolvimento e oportunidades igualitárias, seja colaborador, seja cliente, com calor humano e reconhecimento que todos fazem parte e são fundamentais no processo organizacional.

A empresa toca mesmo o coração. Nossos benefícios não são para alguns cargos, são para todos, as aulas e inglês são para todos. Pode ser alguém da área gerencial, mas pode ser da produção, do suprimentos ou da TI, todos possuem o mesmo direito. (Entrevistado 5, 2020).

Além destes fatores, a Renovigi conta, principalmente, "com sua cultura inclusiva, parece estar no DNA da empresa fazer com que os colaboradores se sintam parte efetiva da organização" (Entrevistado 5, 2020).

Outro fator que chama atenção diz respeito à autonomia nos cargos, e percebe-se que nas organizações exponenciais este atributo é bastante forte, em que as equipes são autoorganizáveis e multidisciplinares, e o desenvolvimento da autonomia é constante.

Quando questionado sobre até onde vai a autonomia dos colaboradores, o Entrevistado 5 (2020) responde claramente que as pessoas cumprem, sim, seus horários e logo com suas obrigações funcionais, mas com muita liberdade, responsabilidade e autonomia.

Se nosso colaborador precisa sair para levar filho ao médico, está tudo bem, ele organiza e vai. Se ele precisa sair para pagar uma conta, está tudo bem. E se ele precisa sair para tomar um café e dar um ar pra cabeça e depois voltar, está tudo bem também. Outro programa muito legal é das frutas, todo dia há frutas da estação disponíveis, e o colaborador pode parar e ir fazer seu lanche a hora que deseja/precisar. (Entrevistado 5, 2020).

Neste modelo de empresa, é fundamental que cada colaborador conheça e entenda sua função e responsabilidades, colaborando efetivamente para o grande objetivo da empresa. Em uma organização exponencial, Ismail et al. (2019) fazem referência ao PTM, afirmando que todos devem conhecer e entender o que precisa ser feito para realização do projeto. Essa maneira de trabalho descentralizada permite maior mobilidade e contato entre os colaboradores, e todos possuem liberdade e responsabilidades nas tomadas de decisões.

Fica claramente perceptível que a empresa atua de forma moderna, com muitos recursos tecnológicos, ligados à informática, hardware e software, processos sofisticados, descentralização e linearidade dos processos. "Nossa equipe de TI já foi avaliada como a melhor do País, por alguns órgãos que avaliam estes processos tecnológicos" (Entrevistado 5, 2020).

Além disso, percebe-se fortemente investimento no desenvolvimento dos colaboradores, através do apoio nos cursos de graduação e pós-graduação e desenvolvimento das pessoas, bem como preocupação com bem-estar, felicidade e liberdade dos colaboradores. "Há incentivo financeiro para colaboradores realizar cursos, graduação, pós, ou cursos de formação, tanto na cidade, país e até fora do País. Cada área possui recursos destinados, tanto para eventos como para capacitações" (Entrevistado 5, 2020). 
Quando questionados sobre as principais características que valorizam no modelo de gestão da Renovigi, percebe-se pelas respostas abaixo que as pessoas realmente possuem papel destaque na organização:

Pessoas, pessoas e pessoas. As pessoas vêm em primeiro lugar. Nossa cultura é voltada a pessoas internas e externas, alinhando excelência no atendimento como o bom-senso nos trouxe até aqui, e segue nos levando ao futuro. (Entrevistado 4, 2020).

Corroborando com esta afirmação, outro colaborador afirma que a característica mais importante é o valor da empresa. "Trate os outros como gostaria de ser tratado. Não é apenas uma frase bonita, é algo visível no sentido de tratamento com os clientes como no tratamento do colaborador" (Entrevistado 3, 2020).

Com relação à percepção dos colaboradores e gestores sobre a empresa, fica clara a satisfação dos gestores e colaboradores em trabalhar na Renovigi. Como citado pelo Entrevistado 5 (2020), "a Empresa encanta os olhos, trabalha muito com o calor humano, gosta de ver e sentir os sorrisos no rosto dos colaboradores, oferecendo benefícios à todos, sem preconceito de funções ou cargos".

Também, percebe-se contentamento com a forma de gestão em âmbito geral, bem como a forma como é gerido o setor de Recursos Humanos e sobre a política de gestão de pessoas. Percebe-se isso na declaração a seguir: "os colaboradores deste setor mostram principalmente preocupação com o time que compõe a empresa, dando atenção individualizada as pessoas. Muito acontece pela forma de tratamento, sempre com respeito e atenção a todos" (Entrevistado 4, 2020).

Outra afirmação relevante neste mesmo sentido:

\begin{abstract}
Nosso time de Gestão de Pessoas é espetacular. Tem um cuidado diário com nossas equipes e neste momento que estamos passando, está realizando um trabalho incrível. Acredito que todos os projetos e ações realizadas, principalmente no âmbito social, nos traz a motivação para seguir. Não apenas na empresa, mas em nossas vidas. (Entrevistado 2, 2020).
\end{abstract}

Segundo o Entrevistado 5 (2020), a empresa vem de um sonho, e participar desta concretização compromete todos.

\footnotetext{
Uma empresa é seus colaboradores. Quando ela passa a trabalhar em prol do bemestar e da valorização profissional, é que os resultados financeiros e de crescimento aparecem. Somos movidos por pessoas, pela vida delas e por isso: se faz sentir, faz sentido. (Entrevistado 5, 2020).
}

Na mesma linha, o Entrevistado 5 (2020) afirma que a gestão é muito humana, o jeito de agir é muito humanizado, como mostra a certificação pela Great Place to Work (GPTW) - uma consultoria global que apoia organizações a obter melhores resultados por meio de uma cultura de confiança, alto desempenho e inovação -, que coloca a empresa entre as melhores para trabalhar, não existindo uma ou outra ação, é o conjunto, a soma das ações que tornam trabalhar na Renovigi uma imensa satisfação. "A empresa se preocupa com os pequenos detalhes, coisa que nas outras empresas passam despercebidos, mas na Renovigi não passa" (Entrevistado 5, 2020). 
Este modelo de empresa cativa os melhores profissionais, pois, conforme afirmam Ismail et al. (2019), a gestão destas empresas segue modelos totalmente disruptivo em relação aos modelos conservadores e tradicionais, que prioriza o uso da tecnologia, inovação e criatividade. Assim, grandes profissionais buscam empresas e funções diferenciadas para atuar.

A empresa Renovigi, conforme matéria disponível no site da empresa, foi avaliada, pelo segundo ano, a média empresa que mais cresce no País:

\begin{abstract}
A Renovigi também se destacou entre as empresas de infraestrutura, sendo a que obteve maior incremento no segmento. Em 2018, a empresa encerrou o ano com R\$ 150 milhões e estima fechar 2019 com faturamento de 500 milhões. Para 2020, a Renovigi tem como meta atingir R $\$ 1$ bilhão em faturamento e ultrapassar a marca de 320MW de geração de energia. (Dados da empresa).
\end{abstract}

Com este dado é possível destacar as afirmações de Ismail et al. (2019) em sua obra, ou seja, as organizações exponenciais possuem estruturas organizacionais resilientes e flexíveis ao risco. Segundo Ismail et al. (2019, p. 51), as organizações exponenciais pensam grande e precisam sonhar alto, além disso, todas possuem um PTM, em que "alguns pretendem transformar o planeta, outros apenas um setor produtivo".

Em relação ao perfil e desenvolvimento de liderança, a empresa entende que cada colaborador possui características e competências específicas, e cada um é direcionado para vagas e cargos conforme este perfil. A liderança é destaque em alguns colaboradores, e para a Renovigi isso é algo reconhecido e aceitável que não pertença a todos os colaboradores. "Alguns, que são excelentes funcionários, querem seguir carreira como técnicos, não assumindo o papel de líderes, mas a oportunidade existe para todos" (Entrevistado 5, 2020).

Para contribuir, esclarece que o recrutamento e seleção de novos colaboradores é feito de forma mais tradicional, por meio de técnicas de entrevistas, testes psicológicos, dinâmicas, porém, prioriza-se a promoção e desenvolvimento de colaboradores que já fazem parte da empresa. Estes processos de seleção e promoção possuem papel fundamental, pois, entendendo os valores e missão da empresa, contrata-se pessoas com o perfil que vai ao encontro desta cultura, onde o conhecimento técnico não é determinante para a contratação. É uma empresa inovadora, isso está em seu DNA. "A base dos nossos valores conduz muito o negócio, trate os outros como gostaria de ser tratado" (Entrevistado 5, 2020).

Como a empresa começou com público jovem, com o crescimento da empresa, colaboradores com mais experiência foram contratados e valorizam muito o ambiente de trabalho, ficando claro os benefícios de mesclar a juventude com profissionais com mais experiência. Porém, como diz o Entrevistado 5 (2020), não existe receita de bolo para contratação de pessoas, as habilidades técnicas são importantes, mas não são determinantes para trabalhar na Renovigi.

Quando questionados sobre a forma que ocorre os feedbacks e também sobre os processos formais de avaliação de desempenho, identificamos que os feedbacks ocorrem de forma bem natural e com constância entre gestores e seus times: "Sim, recebo muitos feedbacks sobre o meu trabalho, mas não existe nada formal sobre a avaliação do desempenho" (Entrevistado 3, 2020). 
No que diz respeito ao processo de comunicação organizacional, percebe-se que este é outro ponto forte da empresa, flui de forma natural entre os colaboradores e gestores, sempre com muito respeito, mas busca melhoria contínua: "buscamos através do nosso trabalho melhorar cada dia mais a comunicação organizacional" (Entrevistado 2, 2020); "Os Gestores são muito abertos para dialogar, até mesmo o CEO, você pode chegar, sentar e conversar a hora que precisar" (Entrevistado 4, 2020).

Para as tomadas de decisões, propicia-se a participação de todos, respeitando a autonomia entre os setores. A autonomia existe, inclusive, nos horários, onde o colaborador tem liberdade de decidir os horários de trabalho: "A gente quer que as pessoas cresçam, e para isso elas precisam ter autonomia" (Entrevistado 5, 2020).

A empresa une os processos tradicionais aos tecnológicos, aproveitando muito bem ambos os processos, mas tem uma tendência forte ao uso de tecnologias, por sua cultura e ramo de atuação. "A tecnologia é sim nossa aliada" (Entrevistado 3, 2020).

Outra prática natural da empresa que auxilia muito nos processos de comunicação e desenvolvimento de equipes são as reuniões:

Os gerentes fazem reuniões com seus times, e tomam decisões sobre as ações que devem ser executadas, bem como sobre o orçamento que cada setor tem disponível para fazer investimento em capacitações ou onde achar necessário. O fácil acesso aos gestores é motivo de orgulho para os funcionários. (Entrevistado 5, 2020).

Quando questionados sobre as pesquisas de clima organizacional, verifica-se que a gestão da empresa tem clareza dos pontos bons e daquilo que precisa ser desenvolvido, pois, através dos resultados das pesquisas internas, são avaliados os pontos e divulgados os resultados aos colaboradores. "Nossas pesquisas de clima são muito sérias, priorizamos análise nos pontos a serem melhorados. Todos os resultados são amplamente divulgados aos colaboradores. A gente faz questão de divulgar a nota" (Entrevistado 5, 2020).

Ao questionar os entrevistados sobre as características mais valorizadas, muitas contribuições e relatos demostram orgulho, satisfação e motivação por trabalharem na empresa, inclusive, relatam que pretendem seguir com seus empregos e construir carreira dentro da organização. "Me vejo e imagino eu daqui alguns anos na Renovigi. Me sinto bem e realizada trabalhando lá" (Entrevistado 1, 2020). "Sim, porque tenho paixão pela cultura Renovigi e pela Renovigi" (Entrevistado 4, 2020).

A principal característica é o "modelo de gestão da Renovigi, onde os colaboradores valorizam muito o incentivo à capacitação e o respeito a opinião deles, trate os outros como gostaria de ser tratado, não é apenas uma frase bonita" (Entrevistado 3, 2020).

"A Renovigi incentiva muito a prática da empatia, fazendo parte da cultura organizacional entre os gestores, contagiando todos os colaboradores com o exemplo prático da aplicação dos conceitos do conviver bem e para o bem dos colaboradores e da empresa" (Entrevistado 2, 2020).

A empresa prioriza o desenvolvimento de talentos e promoções internas. No processo de integração, o CEO explica a cultura da empresa, praticamente não existindo resistência sobre as ações da mesma. É claro que essas percepções mudam, pois com o passar do tempo as pessoas mudam seus planos e suas ambições, porém, é totalmente satisfatório saber que neste 
momento ninguém pensa em mudar de organização ou mesmo ser empresário deste ou outro ramo. "É um orgulho saber que temos alguns colaboradores que iniciaram como estagiários e hoje ocupam cargos de gestão na empresa, inclusive em áreas super-reconhecidas, pelo seu desenvolvimento, a exemplo da TI" (Entrevistado 5, 2020).

Neste contexto, é inegável que o papel do líder é extremamente importante, conduzindo situações e processos de forma que todos possam ter a oportunidade de dedicar-se ao máximo na busca de novos e bons resultados organizacionais.

Em relação aos benefícios, a empresa possui muitas possibilidades. Dos citados, percebe-se que vão dos tradicionais até alguns extremamente criativos e inovadores. Também vários benefícios se estendem a familiares/dependentes. Dentre os citados, vale destacar: plano de saúde estendido a familiares, vale-alimentação, vale-transporte e Plano de Participação dos Resultados e os mais valorizados pelos colaboradores são o inglês gratuito e bolsa de estudos para graduação e pós-graduação, os quais motivam os funcionários para a satisfação com a organização, ajudando na retenção de talentos. "A cultura da valorização do colaborador e de dar oportunidade de crescimento pessoal e profissional" (Entrevistado 3, 2020).

Importante destacar a satisfação dos colaboradores entrevistados, bem como a relação direta que este fator influencia no clima organizacional da empresa. Conforme Chiavenato (2010), o clima organizacional está diretamente relacionado com a percepção que os colaboradores possuem em relação à organização, desde aspectos financeiros, políticos, formas de gestão, até de liderança.

Os salários são baseados na renda nacional e a empresa não possui um plano de cargos e salários formal, justamente para privilegiar a meritocracia. O crescimento da empresa é muito veloz e os planos de cargos e salários engessariam o processo.

Não somos muito adeptos a planos de cargos, acho que cada um deve receber por aquilo que apresenta e desenvolve. Precisamos entender a história do colaborador dentro da empresa, não tem como esperar por prazos, o crescimento é muito ágil e precisamos acompanhar com os cargos também. (Entrevistado 5, 2020).

As promoções internas são realizadas pelos gerentes, mas não existe nenhuma dúvida sobre a meritocracia nas promoções. "A meritocracia está 100\% presente" (Entrevistado 4, 2020).

Existem processos internos de seleção para ocupação de vagas superiores. "Acredito que a empresa sempre busca valorizar seus colaboradores” (Entrevistado 2, 2020).

Para encerrar o processo de análise dos dados, aborda-se, de forma geral, uma característica que ficou expressamente visível nas respostas dos colaboradores que participaram das entrevistas, que pode ser designada como felicidade, ou seja, a satisfação, a emoção e a motivação dos colaboradores levam a entender que este sentimento está aliado ao dia a dia da organização, em seus princípios, metas e formas de relacionamento com os clientes internos e externos.

Importante abordar as ideias de Hsieh (2010), que relata a experiência de trabalho da empresa Zappos - que faz parte do grupo Amazon -, empresa conhecida pela paixão dos colaboradores em fazer parte e executar suas funções no dia a dia. O autor afirma que a cultura da empresa de sucesso é construída com envolvimento dos seus funcionários, destacando que os valores corporativos não devem dizer respeito apenas à Zappos, e sim à vida, assim, jamais serão 
esquecidos. Para o autor, envolver os funcionários em torno de um propósito maior é o estado mais pleno de felicidade, relacionado a ser parte de algo maior do que si próprio e que tenha significado para você.

Se alguém lhe pedisse para dizer seus valores corporativos ou sua declaração de missão sem consultar, você conseguiria? As pessoas tentam saber como os funcionários da Zappos de alguma maneira se lembram de todos os 10 Valores Fundamentais de cor. Para mim, é simples... é fácil quando os valores fundamentais da sua empresa são aqueles que se aplicam não apenas ao trabalho, mas à vida. (Hsieh, 2010, p. 176).

A partir de algumas experiências implementadas na Zappos, a empresa conseguiu se destacar e receber vários prêmios de destaque no quesito clima organizacional. Também, Hsieh (2010) revela que a motivação maior para a criação da empresa foi proporcionar felicidade às pessoas, principalmente aos seus funcionários.

"Não somos o tempo todo felizes, nem a semana toda, mas precisamos criar movimentos que propiciem cada vez mais a felicidade e bem-estar de nosso colaborador" (Entrevistado 5, 2020).

\section{CONSIDERAÇÕES FINAIS}

Muito gratificante a experiência de estudar, interagir e ouvir parte, mesmo que um recorte pequeno, da empresa, mas que demonstrou tamanha profundidade e relevância para este estudo. Ficou claro que a tecnologia é um dos fatores primordiais tanto para o surgimento quanto para a manutenção dos processos nestas empresas denominadas exponenciais, mas que tudo acontece pelas mãos dos colaboradores. Além disso, modelos, métodos, planos e pensamento inovador é caminho principal para romper com o modelo tradicional, fazem os mesmos negócios, mas de uma forma moderna, ágil dinâmica e principalmente consciente, enxergando nas pessoas a solução para os problemas e inovações necessárias para a plenitude organizacional.

Neste contexto de modernidade, tecnologia e dinamismo fica claro que alinhado a tudo isso está a Gestão de Recursos Humanos, que pensa e atua com a mesma modernidade e dinamismo dos processos de criação e produção, e que alinha os processos legais ao cuidado com cada colaborador em suas funções.

$\mathrm{Na}$ Renovigi, a área de gestão de pessoas se destaca pelos processos de comunicação das equipes (times), autonomia, flexibilidade, amplo pacote de benefícios, perspectivas de carreira, crescimento profissional e meritocracia.

Pensa e propõe estratégias gerais de carreira, saúde, bem-estar para a estrutura geral da empresa, mas também pensa os processos de recrutamento, seleção e promoção com base no desenvolvimento individual e competências de cada colaborador, não se preocupando exatamente com a experiência adquirida do candidato, mas com o potencial que ele possui para desenvolver-se e agregar ao quadro de colaboradores da Renovigi.

Para que uma empresa se desenvolva neste formato, com crescimento exponencial, é fundamental que todos que fazem parte dela sintam-se completamente engajados e empolgados com o sucesso da empresa, pois este sucesso global, certamente, também será o sucesso individual. 
Como sugestão, fica a proposta de novos estudos, nesta e em outras áreas da empresa, para contribuir ainda mais com o meio acadêmico/científico, e também fica a sugestão de formalizar com regularidade as avaliações de desempenho, pois aliados a processos de feedbacks a avaliação de desempenho pode estreitar ainda mais os laços de relacionamentos entre a organização e seus colaboradores.

\section{REFERÊNCIAS}

Beuren, I. M. (2012). Como elaborar trabalhos monográficos em contabilidade (3a ed.). São Paulo: Atlas.

Bergamini, C. W. (1997). Motivação nas organizações (4a ed.). São Paulo: Altas.

Chiavenato, I. (2010). Comportamento organizacional: a dinâmica do sucesso das organizações (2a ed.). Rio de Janeiro: Elsevier.

Dmitruk, H. B. (2012). Cadernos metodológicos: diretrizes do trabalho científico (8a ed.). Chapecó: Argos.

Drucker, P. F. (1962). A nova sociedade: anatomia do sistema industrial. Rio de Janeiro: Fundo de Cultura.

Fernandes, J. A. T., \& Rosa, C. R. (2013). O clima organizacional: um conceito motivador para redução do turnover. Contribuiciones a La Economia, 2013(8).

Gil, A. G. (2010). Como elaborar projetos de pesquisa (5a ed.). São Paulo: Atlas.

Hsieh, T. (2010). Satisfação garantida. Rio de Janeiro: Vida Melhor.

Ismail, S., Malone, M. S., \& Geest, Y. V. (2019). Organizações Exponenciais. Por que elas são 10 vezes melhores, mais rápidas e mais baratas que a sua (e o que fazer a respeito). Rio de Janeiro: Alta Books.

Lakatos, E. M., \& Marconi, M. A. (2011). Metodologia científica (6a ed.). São Paulo: Atlas.

Lemos, C. (2000). Inovação na Era do Conhecimento. Parcerias Estratégicas, 5(8), 157-180.

Luz, R. (2003). Clima organizacional. Rio de Janeiro: Qualitymark.

Mascarenhas Bisneto, J. P., \& Lins, O. B. S. M. (2016). Gestão da inovação: uma aproximação conceitual. Revista Brasileira de Gestão e Inovação, 3(2), 86-109.

Matos, F., \& Lopes, A. (2008). Gestão do capital intelectual: a nova vantagem competitiva das organizações. Comportamento Organizacional e Gestão, 14(2), 233-245.

Maximiano, A. C. A. (2009). Introdução à Administração (6a ed.). São Paulo: Atlas.

Ambiente Energia. (2019). Michel Teló é contratado como embaixador da Renovigi Energia Solar. Recuperado em 10 outubro, 2020, de https://www.ambienteenergia.com.br/index.php/2019/03/michel-telo-e-contratado-comoembaixador-da-renovigi-energia-solar/35884

Minayo, M. C. S. (2001). Pesquisa social: teoria, método e criatividade. Rio de Janeiro: Vozes.

Oliveira, M. A. (2010). Comportamento organizacional para a gestão de pessoas: como agem as empresas e seus gestores. São Paulo: Saraiva.

Rachel, L. A., \& Salomão, A. H. (2011). Cultura e clima organizacional como estratégias de Impacto no desempenho. Revista Eletrônica Machado Sobrinho, 4(2), 1-14.

Richardson, R. J. (2014). Pesquisa Social, métodos e técnicas (3a ed.). São Paulo: Atlas.

Robbins, S. P., Judge, T. A., \& Sobral, F. (2010). Comportamento Organizacional (15a ed.). São Paulo: Pearson Prentice Hall.

Santos, G. (2018). Organizações exponenciais: uma análise do desenvolvimento de startups na Incubadora Midi Tecnológico. Tese de doutorado, Universidade Federal de Santa Catarina, Florianópolis, SC, Brasil. 
Silva, R. O. (2008). Teoria da administração. São Paulo: Pearson Prentice Hall.

Stewart, T. A. (1998). Capital intelectual. Rio de Janeiro: Campus.

Sveiby, K. E. (1998). A nova riqueza das organizações. Rio de Janeiro: Campus.

Tidd, J., \& Bessant, J. (2015). Gestão da Inovação (5a ed.). Porto Alegre: Bookman.

Vecchio, R. P. (2009). Comportamento organizacional: conceitos básicos. São Paulo: Cengage Learning. 